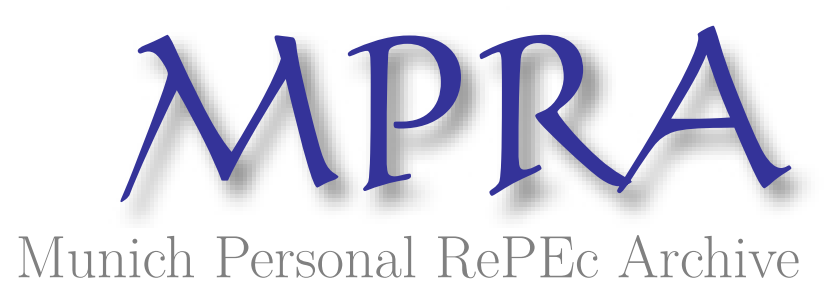

\title{
Can Innovation Save Us? Understanding the Role of Innovation in Mitigating the Covid-19 Pandemic in ASEAN-5
}

\section{Economies}

Layos, Jerk Joshua Meire and Pena, Paul John

De La Salle University, De La Salle University

2 May 2020

Online at https://mpra.ub.uni-muenchen.de/100152/

MPRA Paper No. 100152, posted 06 May 2020 14:23 UTC 


\title{
Can Innovation Save Us? \\ Understanding the Role of Innovation in Mitigating the Covid-19 Pandemic in ASEAN-5 Economies
}

\author{
Written by: \\ Jerk Joshua Meire G. Layos ${ }^{1}$ and Paul John M. Peña ${ }^{1}$ \\ ${ }^{1}$ De La Salle University School of Economics
}

\begin{abstract}
The novel coronavirus (Covid-19) pandemic raises the question of whether innovation can save humanity. Indeed, as it always has, innovation is the path towards finding solutions such as vaccines, treatments and policies that mitigate the further spread of the virus. Since the announcement of a global pandemic on March 12, 2020, countries with relatively high levels of innovation remain high on the world rankings on new cases and deaths while countries considered relatively lower in innovation are not. We test the relationship between innovation systems and the ability of its pre-epidemic state to address the pandemic. We use a two-step System Generalized Method of Moments (GMM) to test this relationship using cases from the ASEAN-5 economies and their respective levels of innovation as reported in the Global Innovation Index. We find that the relationship between the level of innovation and a country's ability to respond to the crisis to be significant and positive. We also find that search interest, an indicator of market response within an innovation context, to have a significant negative relationship with crisis management. We provide some preliminary analyses and insights on these two key findings as well as policy recommendations concerning innovation systems.
\end{abstract}

Keywords: coronavirus, covid-19, innovation systems, Triple Helix, ASEAN JEL Codes: O30, I10, F15 


\section{Introduction}

Countries with a well-functioning national innovation system as forged by the synergy among university, government and industry, or the Triple Helix, can be expected to respond to health crises relatively better than others that do not. Intuitively, an active Triple Helix is likely to have better institutional preparedness, requisite scientific knowledge, and favorable economic conditions to minimize loss of life in a pandemic. Yet, the novel coronavirus (Covid-19) pandemic continues to hit countries that are ranked higher in the Global Innovation Index 2019 [1] the hardest while countries with lower innovation levels remain, likewise, relatively lower on all critical indicators on the Worldometers Coronavirus Pandemic global tracker [2].

We ask whether innovation can help mitigate the continued loss of many lives to Covid-19 by looking at the relationship between innovation and Covid-19 outcomes in the Association of Southeast Asian Nations founding member states (ASEAN-5) namely Indonesia, Malaysia, Philippines, Singapore, and Thailand.

\section{Methods}

The Global Innovation Index (GII) provides a starting point for showing the relative performance of countries in terms of innovation inputs and outcomes. Inputs to innovation are institutions, human capital and research, infrastructure, market sophistication, and business sophistication. On the other hand, outputs consider knowledge and technology and creative outputs. The GII provides each country with an overall innovation score based on the performance of its innovation inputs and outputs. We take the GII scores of each ASEAN-5 member state to represent their level of innovation. We find that the determinants of the GII score are also consistent with the empirical study of Afzal et al. [3] on the Triple Helix and national innovation systems in the ASEAN-5. Assuming that determinants of the GII score which include institutional considerations, knowledge 
and human capital (i.e., inputs to innovation), and the ability to turn useful knowledge into innovations (i.e., outputs of innovation) are well-functioning, it would be logical to expect countries with high scores to manage the pandemic well.

To understand how well a country performs in its handling of Covid-19 cases, we track the rate of change in the ratio between the rate of recovery and growth rate of new cases, and the rate of change in new deaths relative to the growth rate of new cases. Simplified, we get a ratio of new recovered cases and new deaths and denote it as COVIDRatio, tracked bi-weekly. A higher ratio is favorable as it would indicate that more lives have been saved (i.e., higher recovered cases) or that fewer lives are likely to be lost to Covid-19. (i.e., lower death cases). We use raw data from Worldometers Coronavirus global tracker and confirm discrepancies, if any, with official sources of data including ministries of health using web scrubbing protocols.

Finally, we take the search interest of Covid-19-related keywords for each country in the ASEAN5 to determine the level of demand-side activity through what is known as infodemiology [4]. We denote this variable as SearchInterest. Searches on Google can be considered as an innovation outcome as users have the appropriate device, connectivity, and knowledge on how to use the internet to achieve specific tasks (i.e., in this case, to get information). Search activity also indicates participation in the innovation economy. Table 1 shows the keywords used for tracking search interest via Google Trends Coronavirus Feature [5].

Both the Covid-19 ratio and Google Search Interest data are from February 15 to April 15, 2020, tracked bi-weekly, processed using three-day averages to minimize erratic changes seen in daily data. 
Table 1

Keyword architecture used for tracking Search Interest on Google

\begin{tabular}{|c|c|c|}
\hline Disease/Situation & Solution & Sources \\
\hline Covid & Medicine & Updates \\
Coronavirus & Treatment & President/Prime Minister \\
Covid-19 & Vaccine & Ministry/Department of Health \\
Pandemic & Symptoms & \\
Emergency & Hospitals & \\
Virus & Clinic & \\
\hline
\end{tabular}

Source: Authors' representation.

Note: Some words in English were translated to Bahasa or Thai

We use the Generalized Method of Moments (GMM) given the presence of endogeneity within the model and relatively few and shorter periods under study. We follow the rule of thumb by Höffler et al. [6] which reveals a downward bias due to weak instrumentation making system GMM the more efficient model to use. We apply a two-step system GMM process to address efficiency, robustness, heteroscedasticity and autocorrelation [7]. We formalize our empirical model:

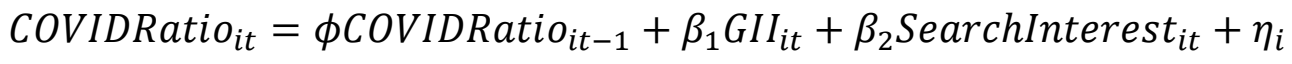

where $\phi$ determines the speed of how countries adjust with the Covid-19 pandemic, $\beta_{1}$ and $\beta_{2}$ shows the marginal contribution of GII and Search Interest on the recovery-death ratio, and $\eta_{i}$ captures some unobserved variables. In a two-step GMM, we set GII and its lag as internal instruments and set SearchInterest and bi-weekly dummies as external instruments.

We regress the COVIDRatio $i t$ with its lagged variable, with GII $_{i t}$ as the predetermined variable and SearchInterest St $_{\text {as }}$ an explanatory variable. Using post-estimation tests, we find that the model is robust; it also passes the tests for autocorrelation and instruments specification. 


\section{Discussion}

Table 2 shows a significant positive effect of innovation and the lagged dependent variable and a significant negative effect of search on the COVIDRatio. This outcome implies that countries adapt to the crisis relatively well given their level of innovation, which ultimately may result in either an increase in the recovery rate, decrease in death rate, or both.

Table 2

Two-Step SysGMM Results with COVID Recovery-Death Ratio as the dependent variable

\begin{tabular}{|lr|}
\hline \multicolumn{2}{|c|}{ Variables } \\
\hline L_COVIDRatio & Two-Step SysGMM \\
GII & $.0749187^{*}$ \\
Search Interest & $3.378037^{* *}$ \\
\hline Biweekly Dummies & $-4.44315^{* *}$ \\
Number of Observations & Yes \\
F Statistic & 14 \\
AR (2) & 94.17 \\
Hansen Statistic & 0.476 \\
\hline
\end{tabular}

Note: $* * *, * *$, and $*$ are statistically significant at $1 \%, 5 \%$, and $10 \%$, respectively. Source: Authors' calculations.

This significant positive effect of the level of innovation on the recovery/death ratio confirms our a priori expectation that a well-functioning innovation system indeed fosters health outcomes. This implies that if a country is higher in the GII rankings before the crisis, it is likely more equipped to maintain a high recovery rate and keep death rates low. 


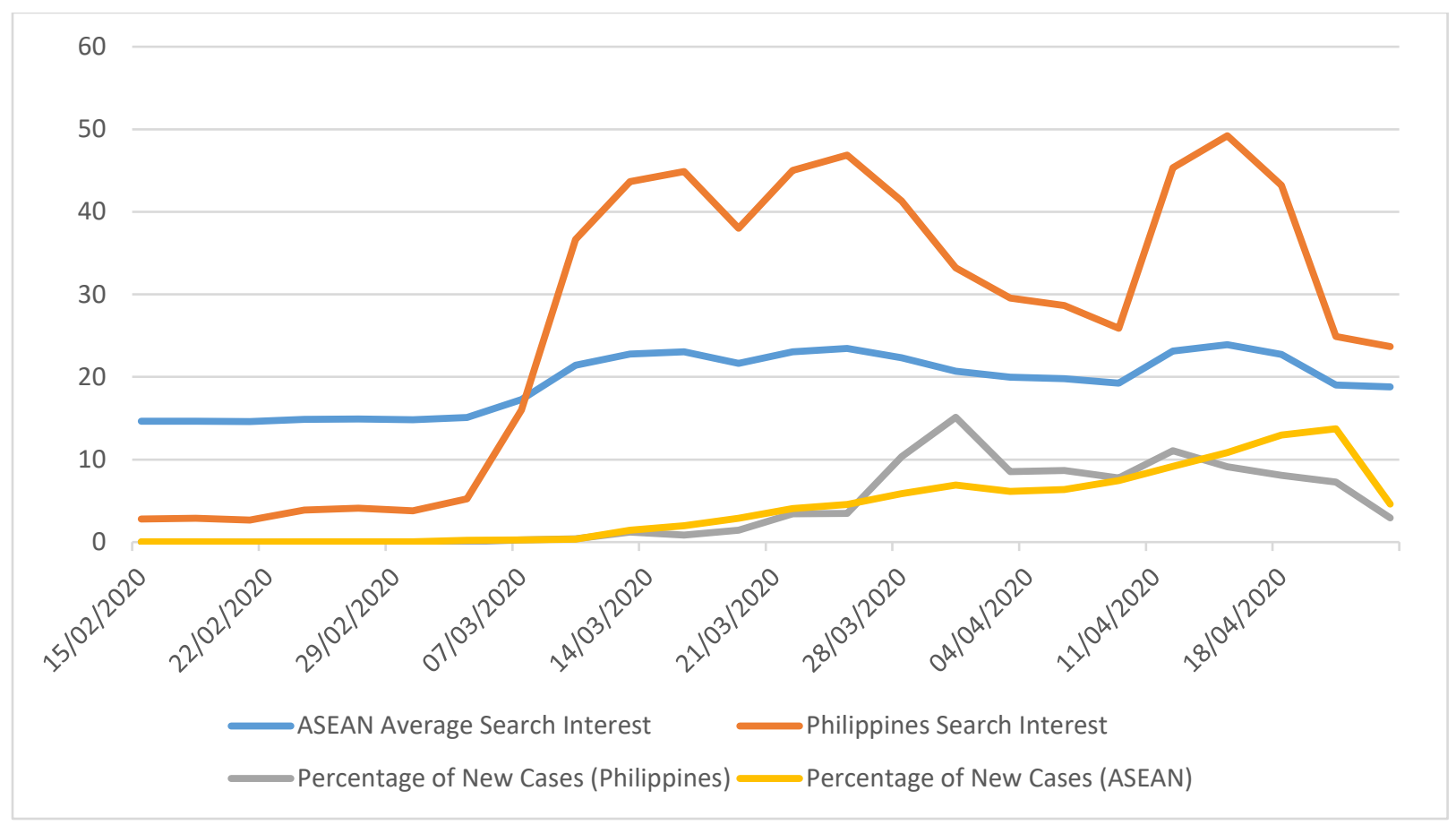

Figure 1. Search interest and three-day rate of change average in new Covid-19 cases in the ASEAN-5 and Philippines as of April 24, 2020.

Source: Google Trends and Worldometers.

One of the seemingly counterintuitive findings is the significant negative effect of search on the recovery-death ratio. One possibility is that as more individuals search online, they are likely to interact with unreliable content which may lead to more inappropriate responses to the pandemic. We cannot account for this possibility in this study, neither theoretically nor empirically.

However, search interest likely grows as cases reported on media serving as a trigger to look for more information via search, as seen in Figure 1. Search interest reacts well with events like the declaration of a pandemic by WHO and whenever cases spike. We find that market reaction through search is a relevant innovation indicator in the context of a pandemic.

\section{Policy Recommendations}

Coordinate testing and tracing innovations and drive the race for a vaccine in ASEAN. Our study shows that there is a significant positive relationship between the level of innovation and the ability 
of a country to manage its Covid-19 cases. In the time of a pandemic, the race to develop innovations in treatments, vaccines, testing, contact tracing, and policy infrastructure can help society navigate the road back to some normalcy [8]. ASEAN economies must reinforce its commitment to coordinate its innovation activities with the race for innovation as an incentive. Afzal et al. (2017) point to the opportunity in boosting the university-industry innovation linkage, which in the context of Covid-19, can fast track the development and diffusion of health innovations.

Reform and upgrade inputs to innovation. As our study establishes the importance of innovation systems in managing a crisis and its ability to respond to it efficiently, we recommend looking into the determinants of innovation, notably the inputs to innovation. Institutional preparedness, the dynamism of knowledge creation and its flow-through to innovation are the safeguards of society against the profound threats to public health and safety.

Reinforce the role of information in public health and innovation systems. Our study shows that individuals respond to information and look for related knowledge online. Information needs to be disseminated regularly and more frequently, especially while in the crisis mode. Subsequent behavior can be influenced dramatically by the availability of factual information. Public officials accountable for the promotion of public health and overall well-being need to use relevant channels more frequently than they did before. Officials need to take advantage of this online search behavior to influence private decisions to move towards socially optimal choices.

\section{Concluding Remarks}

Innovation systems serve a purpose in society. A well-functioning innovation system boosts the readiness of a country for a pandemic. Measures to improve inputs to innovation including institutions, human capital, market and business sophistication will only enhance the ability of a 
country to respond to a pandemic efficiently and effectively, minimizing the profound loss of human lives. We find that innovation systems affect a country's ability to promote better health outcomes, which may be true not only in the time of coronavirus but also in better days. Innovation can save lives - only now we need it more urgently than ever.

\section{Author Contributions}

Conceptualization: Joshua Jerk Meire G. Layos and Paul John M. Peña

Data curation: Joshua Jerk Meire G. Layos

Formal analysis: Joshua Jerk Meire G. Layos and Paul John M. Peña

Investigation: Joshua Jerk Meire G. Layos and Paul John M. Peña

Methodology: Joshua Jerk Meire G. Layos and Paul John M. Peña

Project administration: Joshua Jerk Meire G. Layos and Paul John M. Peña

Resources: Joshua Jerk Meire G. Layos and Paul John M. Peña

Supervision: Paul John M. Peña

Validation: Paul John M. Peña

Writing - original draft: Joshua Jerk Meire G. Layos and Paul John M. Peña

Writing - review \& editing: Joshua Jerk Meire G. Layos and Paul John M. Peña 


\section{References}

[1] Dutta S, Lanvin B, Wunsch-Vincent S editors. The Global Innovation Index 2019: Creating Healthy Lives - The Future of Medical Innovation. $12^{\text {th }}$ ed. Ithaca, Fontainebleau, and Geneva: Cornell University, INSEAD, and WIPO; 2019.

[2] Worldometers [Internet]. Dover (DE): Coronavirus Pandemic Global Tracker - [cited 2020 April 29]. Available from https://www.worldometers.info/coronavirus/.

[3] Afzal MN, Mansur KB, Sulong RS. An Empirical Investigation of Triple Helix and National Innovation System Dynamics in ASEAN-5 Economies. Asian Journal of Innovation \& Policy. 2017 Dec 1;6(3).

[4] Mavragani A. Tracking COVID-19 in Europe: Infodemiology Approach. JMIR Public Health and Surveillance. 2020;6(2):e18941.

[5] Google Trends [Internet]. Mountain View (CA). Coronavirus Feature - [cited 2020 April 29]. Available from https://trends.google.com/trends/.

[6] Höffler A, Bond SR, Temple JR. GMM estimation of empirical growth models. CEPR Discussion Papers/Centre for Economic Policy Research Discussion Papers. 2001.

[7] Roodman D. How to do xtabond2: An introduction to difference and system GMM in Stata. The stata journal. 2009 Mar;9(1):86-136.

[8] Gates B. Gates Notes. The first modern pandemic. [cited 2020 April 9]. Available from https://www.gatesnotes.com/Health/Pandemic-Innovation. 